\title{
Evolving in isolation: Genetic tests reject recent connections of Amazonian savannas with the central Cerrado
}

\author{
Luciana C. Resende-Moreira ${ }^{1,2}$ (D) | L. Lacey Knowles ${ }^{2}$ | Andréa T. Thomaz ${ }^{2}$ \\ Joyce R. Prado ${ }^{3}$ (D) | Andrea P. Souto ${ }^{1}$ | José P. Lemos-Filho ${ }^{4}$ Maria Bernadete Lovato ${ }^{1}$
}

${ }^{1}$ Departamento de Biologia Geral, Universidade Federal de Minas Gerais, Belo Horizonte, MG, Brazil

${ }^{2}$ Department of Ecology and Evolutionary Biology, Museum of Zoology, University of Michigan, Ann Arbor, Michigan

${ }^{3}$ Departamento de Ciências Biológicas, Escola Superior de Agricultura 'Luiz de Queiroz', Universidade de São Paulo, Piracicaba, SP, Brazil

${ }^{4}$ Departamento de Botânica, Universidade Federal de Minas Gerais, Belo Horizonte, MG, Brazil

\section{Correspondence}

Maria Bernadete Lovato, Departamento de Biologia Geral, Instituto de Ciências Biológicas, Universidade Federal de Minas Gerais, Caixa Postal 486, 31270-901, Belo Horizonte, Minas Gerais, Brazil.

Email: lovatomb@icb.ufmg.br

Funding information

Conselho Nacional de Desenvolvimento Científico e Tecnológico; Coordenação de Aperfeiçoamento de Pessoal de Nível Superior, Grant/Award Number: PDSE 99999.003882/2015-02; Fundação de Amparo à Pesquisa do Estado de Minas Gerais; University of Michigan, Ann Arbor

Editor: Hans-Peter Comes

\begin{abstract}
Aim: The effects of past climatic shifts remain enigmatic for the Amazon region, especially for islands of savanna within the tropical forest known as "Amazonian savannas" (AS). These disjunct savanna areas share many plant and animal species with the Cerrado biome in central Brazil (the CC), fuelling debate over historical connections. We evaluate hypothesized corridors between the CC and the AS, and specifically investigate whether a history of isolation versus recent connections is supported by genetic tests.
\end{abstract}

Location: Cerrado and Amazon biomes.

Taxon: Two woody plant species: Byrsonima coccolobifolia and B. crassifolia (Malpighiaceae).

Methods: Analyses of genomic data (SNPs from more than 4,500 loci) in 28 populations, as well as chloroplast DNA (cpDNA), were used to test for parallel geographic structuring between the $\mathrm{CC}$ and $\mathrm{AS}$-an expected structure if putative corridors provided regional connections between different areas of the $C C$ and $A S$, and divergence times between the CC and AS were estimated using a composite-likelihood method based on the site frequency spectrum.

Results: Genomic data, in contrast with cpDNA, generally show strong, concordant genetic structure between the $C C$ and $A S$ in both species, rather than regional grouping of CC with AS populations. In addition, divergence between the $\mathrm{CC}$ and AS predates the Last Glacial Maximum.

Main conclusions: Our results suggest the AS have remained relatively isolated from the $\mathrm{CC}$ even though the strong structure of genomic variation is not shared by cpDNA. We note that past evidence of putative corridors between the CC and AS based solely on cpDNA should be interpreted cautiously since the lack of structure may reflect limited genetic resolution rather than gene flow. As such, the uniqueness of AS may be more pronounced than previously thought, highlighting the importance of protecting these highly threatened areas.

KEYWORDS

Amazon, Byrsonima, Cerrado, corridor, Malpighiaceae, phylogeography, RAD-seq, relict, savanna 


\section{1 | INTRODUCTION}

Climate change has induced historical shifts in landscapes, including the fragmentation of once widespread biomes into relatively isolated patches. The persistence of such populations and the evolutionary dynamics shaping their current genetic structure are commonly considered in studies of the Northern hemisphere following the glacial retreat of the Pleistocene (Hewitt, 2004; Knowles \& Massatti, 2017; Pielou, 1992). However, the impact of past climatic shifts is not unique to these areas. The effects of climatic extremes are worldwide, with documented shifts of biomes leaving behind relict populations (e.g., Bonatelli et al., 2014; Migliore et al., 2013; Ornelas, Ruiz-Sanchez, \& Sosa, 2010). However, tropical regions remain critically understudied relative to their northern counterparts. The evolutionary history of many tropical biomes is also enigmatic because of particularly sparse palynological or fossil evidence (e.g., Jaramillo et al., 2010) and limited or inconsistent support for a range of different hypotheses regarding the magnitude of climate-induced distributional shifts.

Such uncertainty is exemplified by debates over the evolutionary history of the central Cerrado (CC) and Amazonian savannas (AS) of Brazil (Figure 1). The CC is a hyper-diverse, yet relatively understudied savanna biome that covers over 2 million $\mathrm{km}^{2}$. Many plant and animal taxa (including over 70 woody species) are present in the CC and AS, with some AS displaying higher floristic similarity to locations within the CC than to geographically proximate AS (Ratter, Bridgewater, \& Ribeiro, 2003), suggesting past connections between the CC and AS (Prance, 1996; Silva, 1995; Silva \& Bates, 2002), rather than independent long-distance dispersal events (see Pennington, Lewis, \& Ratter, 2006). However, different hypotheses narrate how the retraction of the Cerrado from its former maximum extent might have occurred, which include past connections - that is, corridors - between the Cerrado and areas where AS persist today. Where such corridors might have existed, and which geographic areas they might have connected are still debated. For example, three different corridors between the CC and AS have been proposed: a coastal corridor, a central Amazonian corridor, and an Andes corridor (Haffer, 1967, 1974; Webb, 1991). Depending on the study, support for hypothesized corridors differ, as does the purported timing of past connections between the CC and AS (e.g., Bueno et al., 2017; Quijada-Mascareñas et al., 2007; Savit \& Bates, 2015; Vargas-Ramírez, Maran, \& Fritz, 2010; Werneck, Nogueira, Colli, Sites, \& Costa, 2012). That is, the uncertainty over the geographic location of corridors is paralleled by debate over when such connections might have occurred (e.g., during the Miocene and Pliocene, Pascual \& Jaureguizar, 1990; versus the Pleistocene, Haffer, 1969; Prance, 1982; van der Hammen, 1991), including whether such connections might have been forged during the drier climate of the Last Glacial Maximum, LGM, especially given the lack of support for such late Pleistocene expansion based on palynological evidence (Colinvaux, Irion, Rasanen, Bush, \& de Mello, 2001; Kastner \& Goni, 2003; Mayle, Burn, Power, \& Urrego, 2009).

Here, we address the extent to which the AS have evolved in isolation from the $\mathrm{CC}$ by quantifying population genetic structure of two widely distributed tree species that are common in both the $\mathrm{CC}$ and
AS-Byrsonima coccolobifolia Kunth and Byrsonima crassifolia (L.) Kunth (Ratter et al., 2003). Specifically, we test the degree to which Cerrado populations are genetically distinct from the AS, as opposed to exhibiting parallel geographic structuring of genetic variation within the CC and among AS, as expected if multiple corridors provided regional connections between different areas of the CC and different subsets of AS. We conducted this test using genomic data (i.e., more than 7,000 and 4,500 loci sequenced in 86 and 68 individuals of $B$. coccolobifolia and $B$. crassifolia, respectively), as well as assays of the geographic structure of chloroplast DNA (cpDNA) across an even broader sampling of populations. In addition to the individual histories, we consider the degree to which the taxa show concordant patterns of genetic variation. As ecologically similar, dominant and co-distributed taxa, concordance would lend support to common factors structuring the history of constituent taxa in this diverse biome (Avise, 2004), thereby overriding stochastic processes associated with the biomes dynamic history (Behling \& Hooghiemstra, 2001; Ledru, 2002; but see Massatti \& Knowles, 2014, 2016). Lastly, we estimate divergence times between the CC and AS to determine how long the AS may have been evolving independently of the CC.

\section{2 | MATERIAL AND METHODS}

\section{1 | Study species}

Byrsonima Rich. Ex Kunth is a common genus, with most of its diversity represented by South American savanna taxa, many of which co-occur (Anderson, Anderson, \& Davis, 2006; Ratter et al., 2003). Byrsonima coccolobifolia and B. crassifolia are the most common species from the genus in the Cerrado and in the Amazonian savannas (Ratter et al., 2003), with the range of B. crassifolia extending into the savanna woodlands of Central America and Mexico (Anderson, 1981). Its fleshy fruits are bird-dispersed (Anderson, 1983) and flowers are pollinated by oil-collecting bees, especially Centris species (Benezar \& Pessoni, 2006; Vinson, Williams, Frankie, \& Shrum, 1997).

\subsection{Sampling and DNA extraction}

Population sampling of B. coccolobifolia and B. crassifolia covered both species' ranges across the CC and AS (Figure 1; for details see Table S1.1, Appendix S1 in Supporting Information) and was informed by occurrence data from NeoTropTree (Oliveira-Filho, 2017) and the INCT_-Virtual Herbarium of Flora and Fungi (http:// inct.splink.org.br/index). A total of 158 individuals across 16 populations of $B$. coccolobifolia and 15 populations of $B$. crassifolia were sequenced using RADseq (described below; see also Table 1 and Figure 1). In addition, cpDNA was sequenced in a larger set of populations (i.e., 46 populations and 218 individuals; for detailed sampling information see Appendix S2). Voucher specimens of all sampled populations were deposited in the Herbarium of Departamento de Botânica, Universidade Federal de Minas Gerais (BHCB) and the Herbarium of Universidade Estadual do Oeste do Paraná (UNOP). 


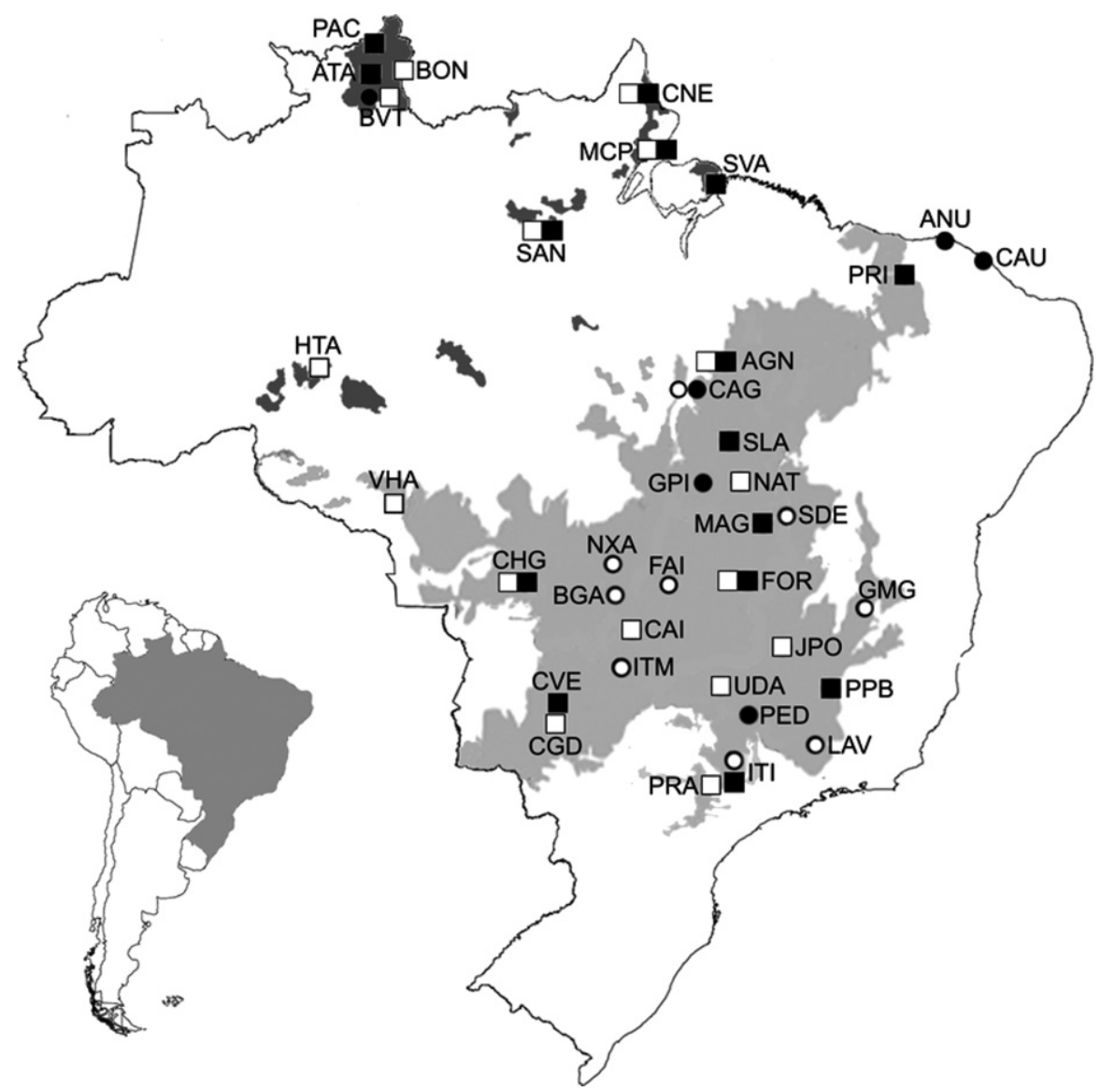

FIGURE 1 Geographic location of sampled Byrsonima coccolobifolia and B. crassifolia populations (white and black symbols, respectively) across the Cerrado (light grey) and Amazonian savannas (dark grey). Populations with both genomic and cpDNA sequences are marked by squares, whereas those with only cpDNA are marked by circles
DNA was extracted using a CTAB protocol (Novaes, Rodrigues, \& Lovato, 2009) from silica-gel dried leaves that were stored at $-20^{\circ} \mathrm{C}$ until DNA extraction. DNA quality was evaluated with Nanodrop $^{\circledR}$ (Thermo Scientific, Walthham, USA) and quantified with Qubit $^{\circledR}$ (Thermo Scientific).

\section{3 | Genomic dataset}

Two genomic libraries were prepared (one for each species) following the double-digest restriction site-associated DNA sequencing (ddRADseq) protocol of Peterson, Weber, Kay, Fisher, and Hoekstra (2012). Briefly, genomic DNA was digested with the restriction enzymes EcoRI and Msel, ligated to adaptors with unique barcodes, pooled and size-selected using Pippin Prep (Sage Science, Beverly, USA), and sequenced on an Illumina HiSeq2500 to generate single-end $50 \mathrm{bp}$ reads at The Centre for Applied Genomics, Toronto, Canada (protocol details given in Appendix S3).

Genomic data for each species were processed separately using the pipeline STACKS 1.35 (Catchen, Hohenlohe, Bassham, Amores, \& Cresko, 2013). Reads were demultiplexed and filtered using the program PROCESS_RADTAGS, with sequences from each individual assembled de novo in USTACKS to identify putative loci, and a catalogue of consensus loci built in CSTACKS. Individual genotypes were identified with SSTACKS (for details of raw data processing see Appendix S3). Individuals were grouped according to their sampling localities in POPULATIONS (STACKS pipeline), and biallelic loci from a minimum of two populations were used in population genetic analysis (described below). We chose this parameter to maximize the number of loci retained (i.e., for any given minimum of missing data, there is a drop out of loci as the number of individuals increases; Huang \& Knowles, 2016). A custom script (available on https://github.com/KnowlesLab; Thomaz, Malabarba, \& Knowles, 2017) was used in $R 3.2 .2$ ( $R$ Core Team, 2017) to exclude loci with high theta values (located within the upper $95 \%$ quantile) and SNPs from the two last nucleotides (Figure S1.1 in Appendix S1) to guard against sequencing and assembly errors. Following this step, the software PLINK 1.07 (Purcell et al., 2007) was used to identify SNPs with a maximum of $20 \%$ of missing data and with a minimum stack depth per individual $(\mathrm{m})$ of five for inclusion in the final dataset.

Processed genomic data resulted in 28,487 SNPs for B. coccolobifolia and 14,855 SNPs for B. crassifolia, and a total of 7,115 and 4,543 loci with one biallelic SNP per locus in each species, respectively; hereafter, we refer to this genetic variation sampled across the genome as "genomic" variation or structure. An average of $81 \%$ of reads per individual were retained, with a mean coverage depth per locus of $23.6 \pm 8.8 \times$ after processing and assembly, which is considered adequate for population genomics inference (see Buerkle \& Gompert, 2013 for details). These loci were identified from the 226 million reads for the 183 individuals sequenced on two Illumina lanes (average of 1,236,269.5 $\pm 684,965.7$ reads per individual; 29 
TABLE 1 Number of individuals sampled, $N$, and estimates of genetic diversity per population of Byrsonima coccolobifolia and $B$. crassifolia (see Figure 1 for distributional map of sampled populations)

\begin{tabular}{lclll} 
Pop & $N$ & $H_{\text {OBS }}$ & $H_{\text {EXP }}$ & $\pi$ \\
\hline Byrsonima & coccolobifolia & & & \\
\hline A-coBON & 4 & 0.053 & 0.049 & 0.058 \\
\hline A-coBVT & 5 & 0.056 & 0.052 & 0.059 \\
\hline A-coCNE & 6 & 0.059 & 0.054 & 0.059 \\
\hline A-coMCP & 6 & 0.059 & 0.056 & 0.063 \\
\hline A-coSAN & 5 & 0.057 & 0.053 & 0.060 \\
\hline A-coHTA & 5 & 0.063 & 0.060 & 0.067 \\
\hline coCAI & 5 & 0.065 & 0.064 & 0.071 \\
\hline coVHA & 6 & 0.064 & 0.065 & 0.072 \\
\hline coCHG & 5 & 0.064 & 0.060 & 0.068 \\
\hline coCGD & 6 & 0.062 & 0.062 & 0.068 \\
\hline coJPO & 6 & 0.067 & 0.068 & 0.075 \\
\hline coUDA & 6 & 0.063 & 0.064 & 0.070 \\
\hline coPRA & 5 & 0.068 & 0.062 & 0.070 \\
\hline Byrsonima & crassifolia & & & \\
\hline A-crATA & 5 & 0.060 & 0.055 & 0.063 \\
\hline A-crPAC & 1 & 0.057 & 0.029 & 0.057 \\
\hline A-crCNE & 5 & 0.065 & 0.067 & 0.076 \\
\hline A-crMCP & 6 & 0.067 & 0.070 & 0.078 \\
\hline A-crSAN & 6 & 0.065 & 0.068 & 0.075 \\
\hline A-crSVA & 6 & 0.067 & 0.071 & 0.079 \\
\hline crPRI & 2 & 0.065 & 0.051 & 0.070 \\
\hline crAGN & 5 & 0.055 & 0.055 & 0.062 \\
\hline crSLA & 6 & 0.056 & 0.055 & 0.061 \\
\hline crMAG & 6 & 0.059 & 0.061 & 0.068 \\
\hline crFOR & 5 & 0.064 & 0.064 & 0.072 \\
\hline crCHG & 5 & 0.058 & 0.059 & 0.067 \\
\hline crCVE & 0.059 & 0.044 & 0.062 \\
\hline crPPB & 5 & 0.056 & 0.040 & 0.060 \\
\hline crITI & 0.057 & 0.059 & 0.066 \\
\hline & 5 & & & \\
\hline AmazOnian & 5 & & & \\
\hline
\end{tabular}

Amazonian savanna populations are identified with an A preceding the population label. Estimates of genetic diversity per population are based on all polymorphic nucleotide positions of filtered genomic data; $H_{O B S}$, observed heterozygosity; $H_{\text {EXP }}$, expected heterozygosity; $\pi$, nucleotide diversity.

individuals were excluded due to large amounts of missing data-for details see Table S1.2 in Appendix S1).

\subsection{Characterizations of genomic variation and structure}

Genetic structure was investigated using two different strategies: principal components analysis (PCA), which does not require any assumptions about the underlying genetic model (Jombart, Pontier, \& Dufour, 2009), and Bayesian clustering, which applies a coalescent model for inferences about genetic structure. The packages "adegenet" 2.0
(Jombart, 2008; Jombart \& Ahmed, 2011) and "ade4" 1.7-2 (Dray \& Dufour, 2007) were used to perform a PCA in R; missing data were replaced by the mean frequency of the most frequent allele. The robustness of PCA results was evaluated using datasets with different levels of missing data (5 and 20\%; see Huang \& Knowles, 2016) and with an additional minimum stack depth per individual of 10. Because these results were qualitatively similar (Figure S3.1 in Appendix S3), the results are not discussed further. Bayesian clustering was performed with the software stRUCTURE 2.3.4 (Pritchard, Stephens, \& Donnelly, 2000), with only one SNP per locus. These analyses included admixture among populations and a correlation among allele frequencies with 1 to 10 genetic clusters $(K)$ tested. Ten independent runs were performed for each $K$-value, with 100,000 burn-in and 300,000 MCMC iterations (the number of burn-in and MCMC iteration were increased when necessary to reach convergence). The most probable number of cluster was identified with Structure Harvester (Earl \& Vonholdt, 2012), and the posterior probability of individual assignment to each cluster was permuted across different runs and visually displayed with ClumPAK (Kopelman, Mayzel, Jakobsson, Rosenberg, \& Mayrose, 2015). A hierarchical analysis with subsets of populations from each inferred genetic cluster was used to test for additional structure within the initial clusters identified by structure (e.g. Massatti \& Knowles, 2014; Papadopoulou \& Knowles, 2015). Hierarchical analyses were performed with the same parameter settings described above, with $K$ values ranging from 1 to the maximum number of populations in each sequential analysis. Note that analyses of genetic structure in B. coccolobifolia suggested the presence of a cryptic taxon (i.e., PCA analysis revealed that the individuals were quite divergent, and distinct, from all the other populations; see Figure 2). Because inclusion of these populations (specifically, coAGN, coNAT and coFOR populations) would confound comparisons of CC to AS (e.g., compare PCA with and without these individuals; Figure 2), the populations were removed and are not included in the geographic structure results.

Tests of the association between geography and genetic structure were performed using two approaches in each species. Isolation-by-distance (IBD) was tested by evaluating whether there was a significant correlation between geographic distance and genetic distance $\left(F_{S T} /\left(1-F_{S T}\right)\right.$, Slatkin, 1995) based on 100,000 permutations with the package "vegan" 2.3-1 in R (Oksanen et al., 2017). Additionally, a Procrustes analysis, which retains the relative longitudinal and latitudinal position of populations to test for an association between genetic variation and geography was used (for additional details see Appendix S3), with the significance of the association, $t_{0}$, (Wang, Zöllner, \& Rosenberg, 2012) evaluated by 10,000 permutations (package "vegan"). The robustness of the association between genes and geography was assessed using a sequential population drop-out procedure (see Knowles \& Massatti, 2017). Geographic structuring of genetic variation was also assessed with additional Procrustes analyses conducted on the CC and AS separately.

Lastly, levels of genetic diversity were characterized for each population using the dataset with all SNPs (i.e., not the dataset with only a single SNP per locus). These include estimation of standard population genetics statistics such as nucleotide diversity $(\pi)$, expected 

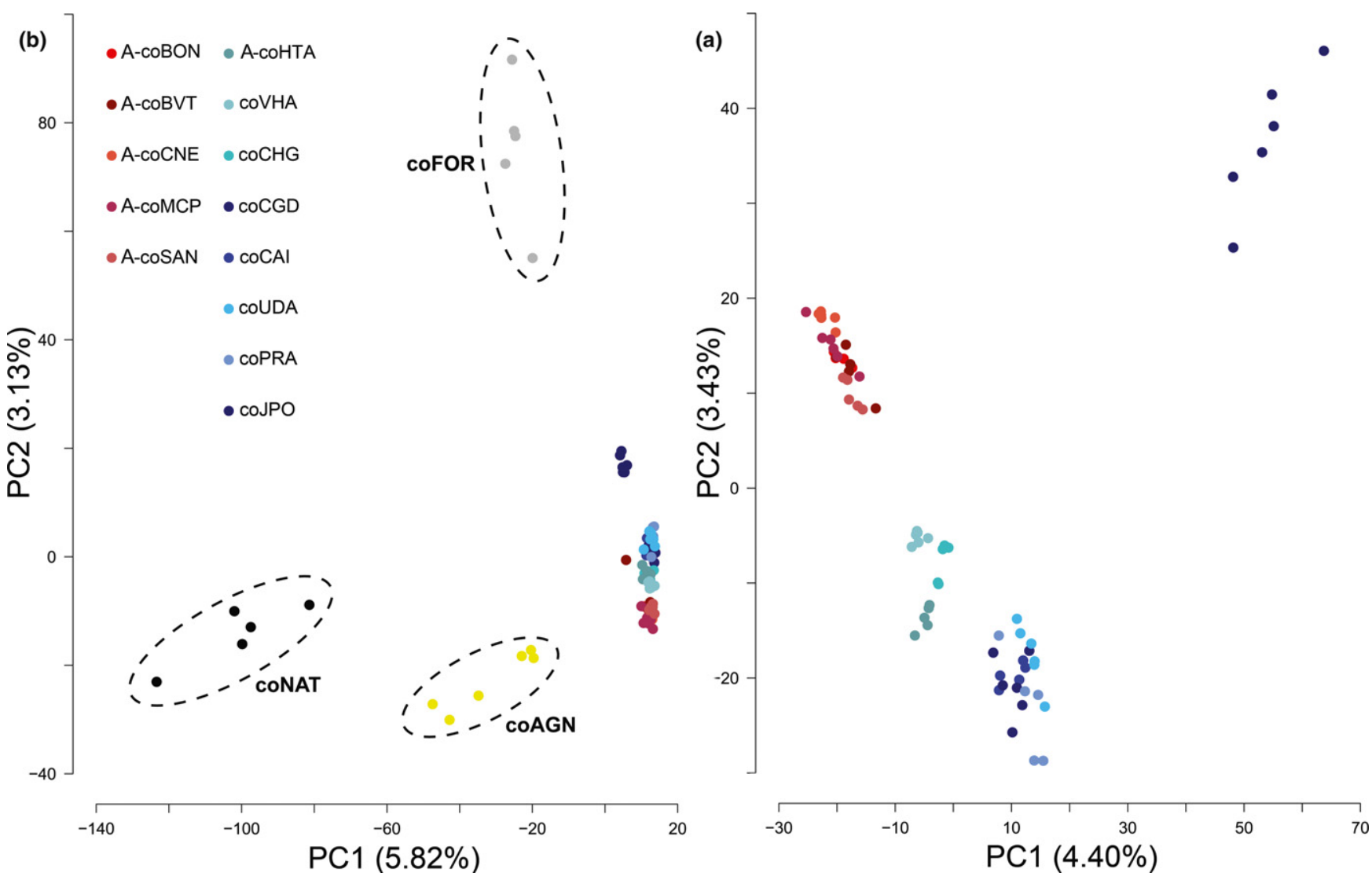

FIGURE 2 Principle Components Analysis (PCA) of Byrsonima coccolobifolia including (a) and excluding (b) populations that revealed cryptic genetic diversity indicative of potentially different species (i.e., the three divergent sampled populations: coAGN, coNAT, and coFOR). The amount of variation explained by each axis is given in parentheses and colours indicate population identity

heterozygosity $\left(H_{E X P}\right)$, observed heterozygosity $\left(H_{O B S}\right)$, and Wright's $F$ statistics $\left(F_{I S}\right.$ and pairwise $\left.F_{S T}\right)$, which were calculated using the POPULATIONS module from the STACKS pipeline (Catchen et al., 2013).

\subsection{Estimates of divergence times}

Divergence times were estimated between the CC and AS using a composite-likelihood method based on the site frequency spectrum (SFS) and implemented in FASTSIMCOAL2 (Excoffier, Dupanloup, Huerta-Sánchez, Sousa, \& Foll, 2013; Excoffier \& Foll, 2011). To improve the accuracy of parameter estimates from the SFS (and following the recommendations of the program; see Excoffier \& Foll, 2011), we fixed the effective population size of the CC, which was calculated directly from the empirical data, whereas the other parameters were estimated (i.e., the population size of AS, $N_{A S}$, the ancestral population size, $N_{A N C}$, and the divergence time, $\left.T_{D I V}\right)$. Specifically, the population size of $\mathrm{CC}$ was calculated from the nucleotide diversity, $\pi$, of fixed and variable sites using a nuclear genomic mutation rate of $7 \times 10^{-9}$ subs/site/generation (Ossowski et al., 2010). This mutation rate was estimated based on spontaneous mutations of Arabidopsis thaliana, a herbaceous annual plant, and therefore divergence times estimated here will tend to be relatively more recent than expected if mutation rates in B. coccolobifolia and B. crassifolia are lower, as suggested for other woody plants (Smith \& Donoghue, 2008; Yang et al., 2015).

Point estimates for each parameter were obtained from the run with the highest maximum likelihood from 40 FASTSIMCOAL2 runs with 100,000 to 250,000 simulations per run, and 10 to 40 expectationconditional maximization (ECM) cycles based upon a stopping criterion of 0.001 as a minimum relative difference between two iterations. Confidence intervals were calculated for each parameter from 100 parametric bootstrap replicates of simulated SFS under a model based on the point estimates. As there is no literature about generation time for those species, divergence time estimates were converted from generations to years assuming a generation time of 3 years, which was observed by a domestication programme to be the age of first fruiting in natural populations (Nascimento W. M. O \& Carvalho J. E. U, Embrapa Amazônia Oriental, personal comm.), although we recognize time estimates may be considerably older if generation times of $10-15$ years for Cerrado trees were applied (Collevatti, Terribile, Rabelo, \& Lima-Ribeiro, 2015; de Lima, LimaRibeiro, Tinoco, Terribile, \& Collevatti, 2014).

Analyses were run with 15 individuals selected from each of the sampled populations that had the smallest amount of missing data (see Table S3.1 in Appendix S3). Since B. coccolobifolia displayed some admixture between the CC and AS, we estimated divergence times 


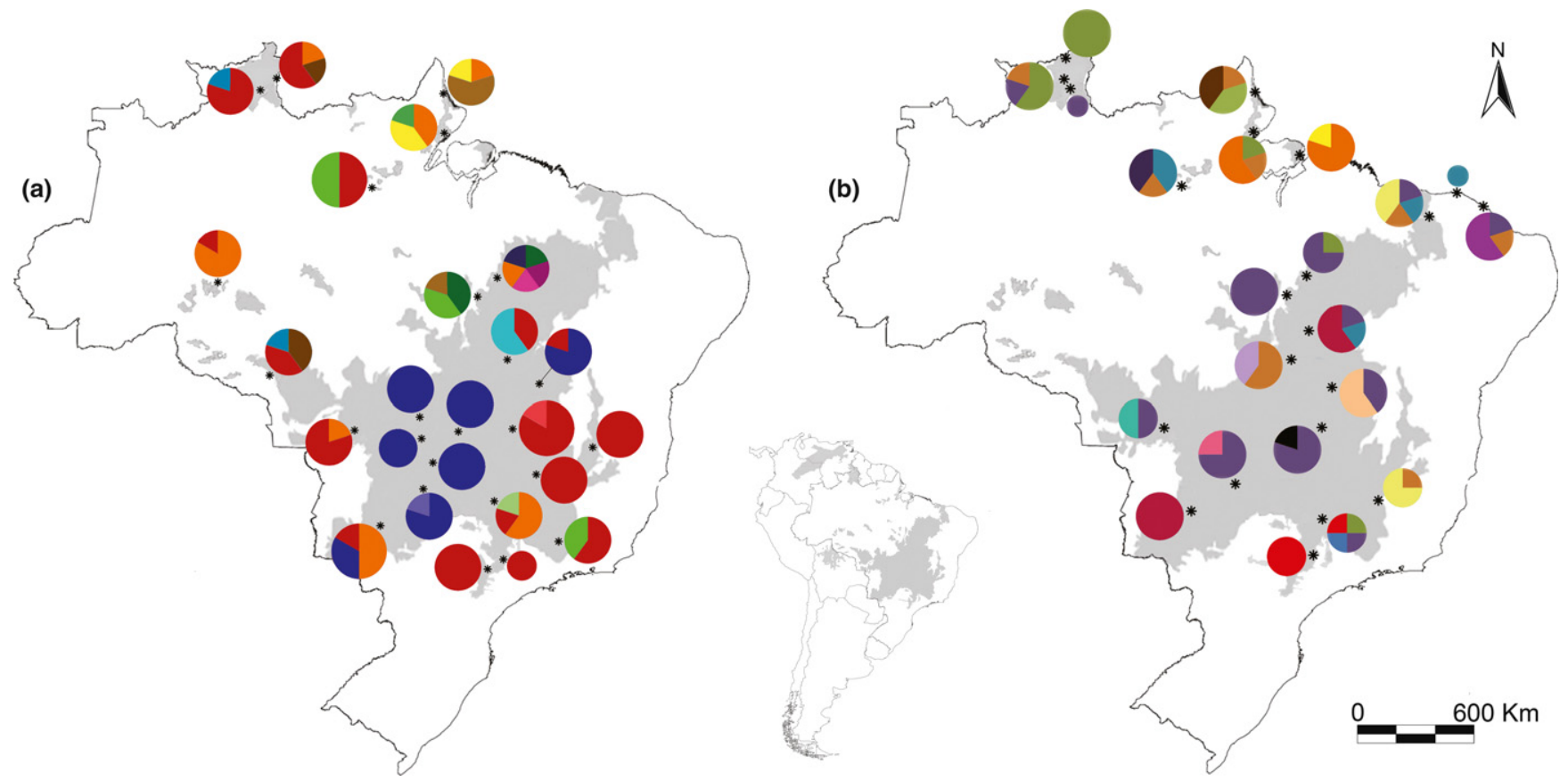

FIGURE 3 Geographic distribution of cpDNA haplotypes (sampling location is marked by small black dot) of Byrsonima coccolobifolia (a) and B. crassifolia (b), with each distinct haplotype represented by a different colour and the number of individuals sampled in each population indicated by the size of the circles. Shaded areas approximate the distribution of the Cerrado (both the central Cerrado and Amazonian savannas)

with and without the populations that displayed admixture (i.e., populations A-coHTA, coCHG and coVHA). We used a python script to calculate the folded joint SFS based on the vcf file from PoPULATIONS (script is available on https://github.com/KnowlesLab; Papadopoulou $\&$ Knowles, 2015). Only loci with a minimum coverage of 10 that were present in all selected individuals were used to calculate the SFS. Divergence times were estimated excluding monomorphic sites (i.e., using the "removeZeroSFS" option in FASTSIMCOAL2) and assuming no migration between the $\mathrm{CC}$ and $\mathrm{AS}$ (this assumption is corroborated by other analyses - see below); note that any violation of this assumption would result in underestimated divergence times (i.e., this assumption is conservative with respect to evaluating whether the AS have had a relatively short history of isolation from the $\mathrm{CC}$ ).

\section{6 | Chloroplast DNA data and analysis}

The trnS-trnG (Hamilton, 1999) and trnH-trnK (Demesure, Sodzi, \& Petit, 1995) regions of chloroplast DNA were sequenced following protocols described in Resende-Moreira et al. (2017) on the ABI 3730XL DNA Analyser (ThermoFisher Scientific, Walthan, USA). A total of 126 sequences of $B$. coccolobifolia (including 49 sequences from Resende-Moreira et al., 2017) and 116 sequences of B. crassifolia, with 1-6 individuals per population (Table S2.1 in Appendix S2), were analysed. Sequences were aligned using the software MUSCLE implemented in MEGA 5.2 (Tamura et al., 2011) and all polymorphisms confirmed by visual inspection. We excluded polymorphisms in microsatellites, which are prone to homoplasy, and indels and inversions were recoded as one mutational step. Haplotypes were identified in DNASP 5.10 (Librado \& Rozas, 2009) and their distribution plotted geographically to highlight haplotype diversity across the range of each species, as well as the distribution of widespread versus localized haplotypes. Additional analyses were performed with cpDNA data to calculate diversity indices and to evaluate population structure (see Appendix S2 for details).

\section{3 | RESULTS}

Measures of genomic diversity were generally similar across populations in both species (Table 1), whereas cpDNA diversity varied somewhat between taxa and among populations (Table S2.1 in Appendix S2), including the fixation of a single cpDNA haplotype in some populations (Figure 3), which contrasts with genomic diversity estimates (see Table 1). Populations with fixed cpDNA were not disproportionately represented by AS populations (i.e., most AS populations were polymorphic in cpDNA), despite their relatively small size and geographic fragmentation.

In both species, the CC populations were genetically differentiated from the AS populations. STRUCTURE analyses (Figure 4) identified separate ancestries for the $\mathrm{CC}$ and the AS (with the exception of coHTA in $B$. coccolobifolia), which was corroborated by pairwise $F_{S T}$-values, which were generally higher between populations from the $\mathrm{CC}$ and AS than among populations within the respective regions (Tables S3.2 and S3.3 in Appendix S3). Likewise, Procrustes analyses showed genetically distinct clusters separating the $\mathrm{CC}$ and $\mathrm{AS}$ regions, except for the coHTA in B. coccolobifolia, which clustered with individuals from the CC (Figure 4a), with a significant association between genes and geography $\left(t_{0}=0.770, p<0.0001\right.$ for $B$. coccolobifolia and 

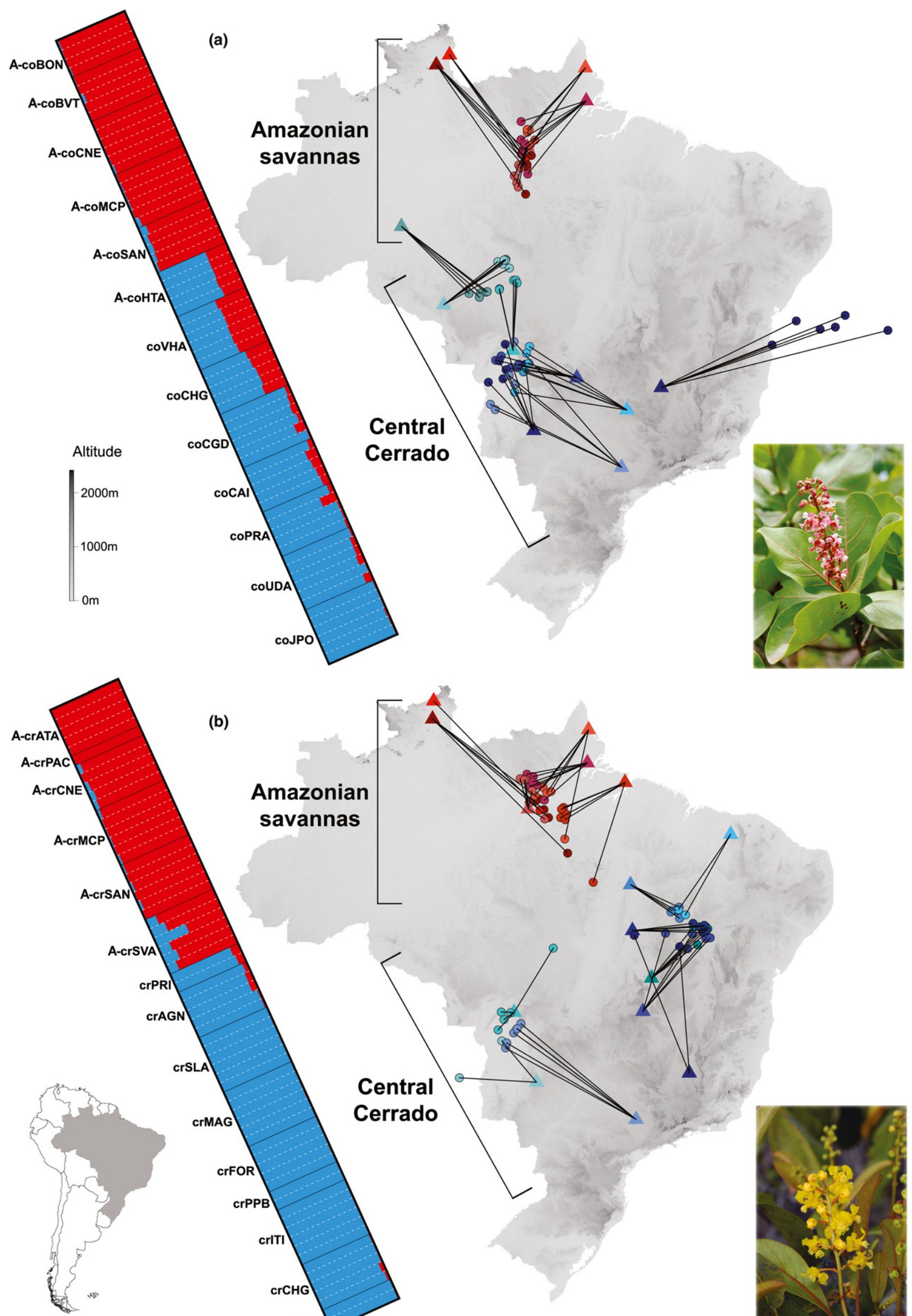

(b)

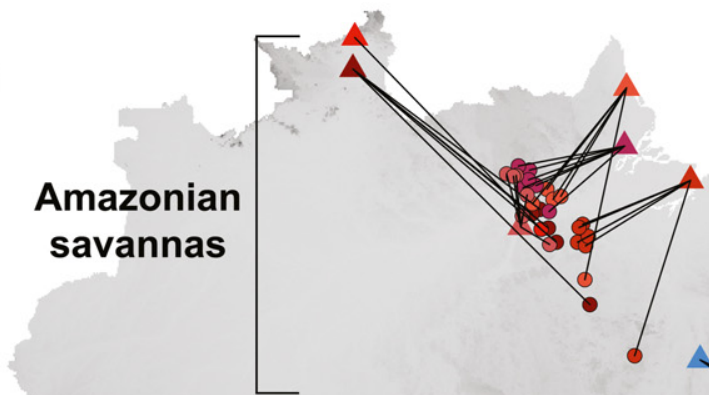


FIGURE 4 Population structure of Byrsonima coccolobifolia (a) and B. crassifolia (b). Barcharts show the most probable number of groups (K) according to STRUCTURE results for each species as different colours along with Procrustes analysis of genetic variation. Each individual in the barchart is demarcated by a white dashed line, and the posterior probability of each individual's ancestry is depicted as the proportion of each colour per individual, whereas populations are labelled and separated by black lines. In each map, the position of an individual in genomic space (shown as circles) relative to sampled locality (show as triangles) is indicated (with individuals colour coded by population). The lines connecting individuals (circles) to localities (triangles) indicate the deviation of an individual genetically from expectations based on their geographic location (i.e., departures from isolation-by-distance). Amazonian savanna populations are identified with an A. Photographs of $B$. coccolobifolia and B. crassifolia were provided by Maurício Mercadante and Daniel Nickrent (source: http://www.phytoimages.siu.edu), respectively

$t_{0}=0.795, p<0.0001$ for B. crassifolia). Sequential population dropout analysis showed the results from the Procrustes analyses are robust (i.e., no single population had a disproportionate effect on the strength of the association between genes and geography, Table S3.4 in Appendix S3). Little admixture between the CC and AS regions was detected in StRUcture analyses, with only one AS population of each species (A-coHTA in B. coccolobifolia and A-crSVA in B. crassifolia) showing any appreciable sign of admixture when all individuals were analysed (Figure 4). Significant IBD was also detected in a correlation analysis between genetic differentiation (measured by $F_{S T}$ ) and geographic distances among populations in both species $(r=0.64$ and $r=0.61, p<0.001$, in B. coccolobifolia and B. crassifolia, respectively).

Within the CC and AS regions, both species showed significant geographic structure. Within the CC, this local substructure was evident in both the hierarchical StRUCTURE analysis (Figure 5), and the separate Procrustes analyses (Figure 6c,d), which showed three genetic clusters in both species. Note that for B. coccolobifolia one of the groups is based on only one population because this is the area where the other three sampled populations appear to belong to a previously unrecognized species (see Figure 2). Separate analyses of the AS populations also detected substructure, with three genetic clusters in STRUCtURE analysis (Figure 5) and the Procrustes analyses (Figure $6 a, b)$. With the primary axes of genetic variation from the Principle Components Analyses separating the CC and AS regions in both species (Figure 4; as well as hierarchical structure detected in the sequential StRUCTURE analyses; Figure 5), the substructure observed within the AS and within the CC clearly accumulated after the separation of AS populations from the CC.

Comparing geographic structuring of genomic data with cpDNA, the genomic variation in $B$. coccolobifolia was generally congruent with the cpDNA (Figure S2.1 and Tables S2.2, S2.4 in Appendix S2), even with broader sampling of the cpDNA dataset (Figure 1). In contrast, cpDNA results for $B$. crassifolia differed from the genomic results and showed a lack of regional or local geographic structure (Figs. 3 and S2.1, and Tables S2.3 and S2.5 in Appendix S2).

Divergence time estimates between the CC and AS were 119,379 and 290,541 years for B. coccolobifolia and B. crassifolia, respectively. These results clearly do not support a LGM divergence even considering that the shortest possible generation time of 3 years was used. We also note the confidence intervals surrounding the parameter estimate for $t$ do not overlap with the LGM. This conclusion is also robust to inclusion of admixed populations of B. coccolobifolia (Table 2). Even

\section{Amazonian savannas}

\section{Central Cerrado}

(a)
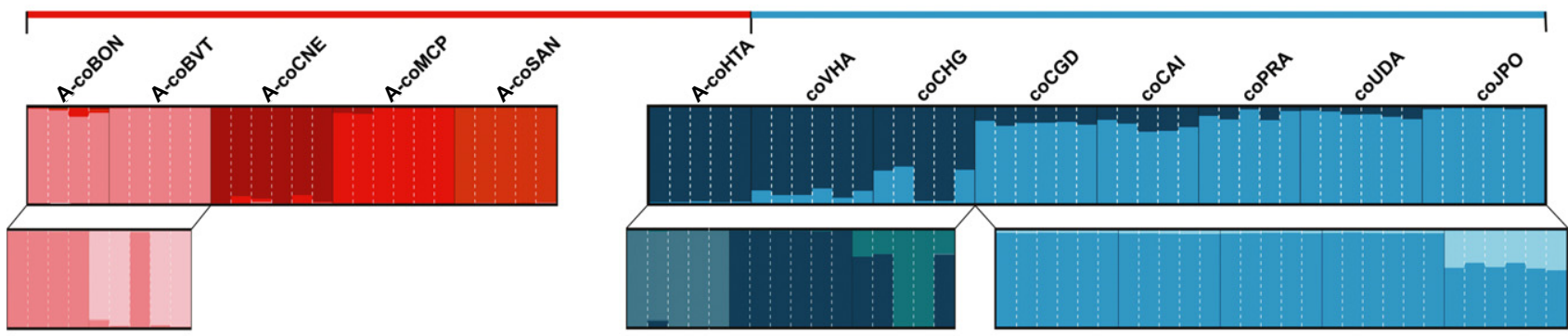

(b)
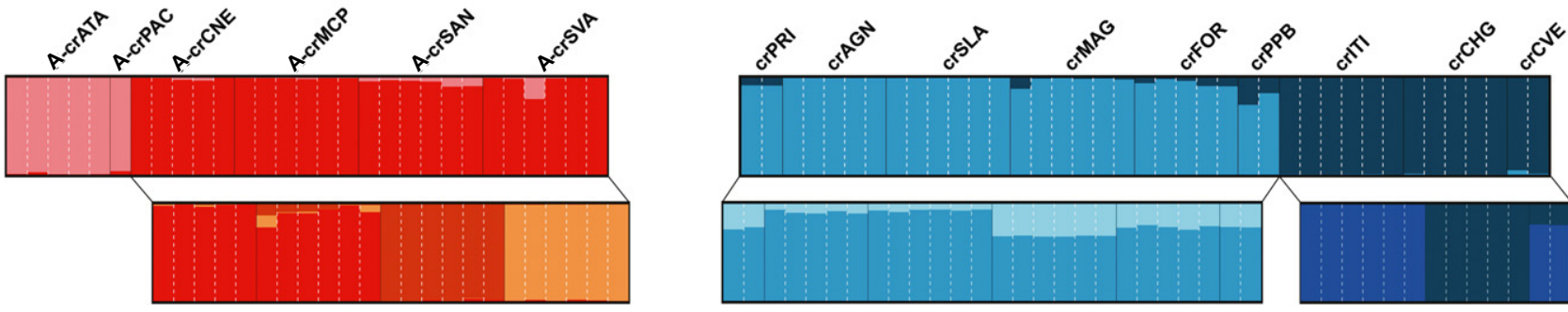

FIGURE 5 Hierarchical population structure of Byrsonima coccolobifolia (a) and B. crassifolia (b) based on sequential, and separate, STRUctuRE analyses of Amazonian savanna and central Cerrado datasets (i.e., data subsets identified from global analyses; see Figure 4). The most probable number of groups $(K)$ is displayed as different colours in each plot, with populations marked by thin black lines, and white lines demarcating sampled individuals with the posterior probability of belonging to each cluster depicted as the proportion of each colour in the bar. Amazonian savanna populations are identified with an $\mathrm{A}$ 

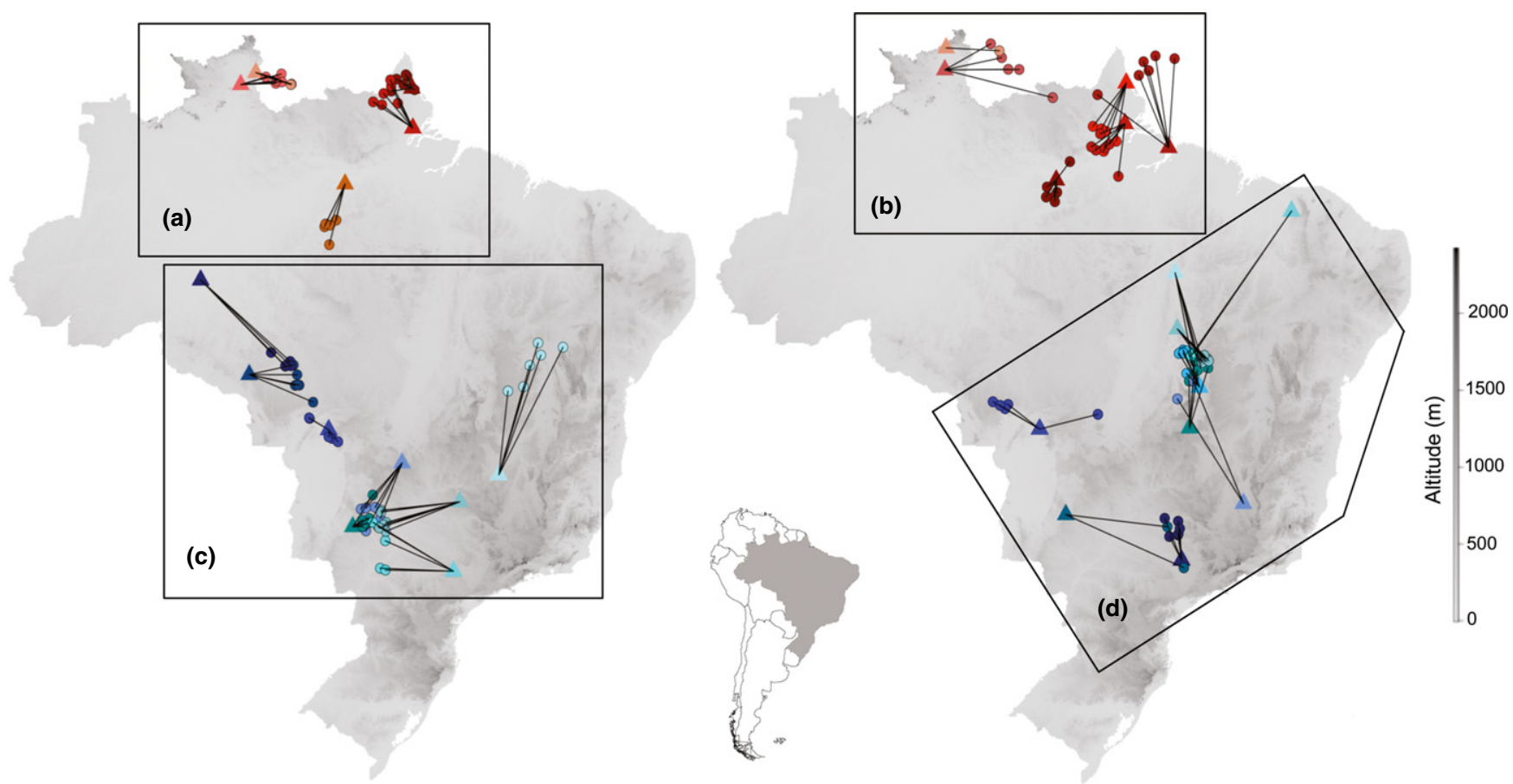

FIGURE 6 Plots of Procrustes analyses carried out separately on regional datasets of the Amazonian savanna (a and b) and central Cerrado populations (c and d) of Byrsonima coccolobifolia and B. crassifolia, respectively. The lines connect individuals (shown as circles) to sampling location (shown as triangles) indicate deviations from the expected pattern of genetic variation based on isolation-by-distance, where longer lines indicate greater departures from expectations based on where an individual was sampled geographically. Colours indicate population identity

with considering potential errors in the mutation rate, the mutation rate would have to be six to twelve times faster than the one applied here to accommodate a divergence time consistent with the LGM. However, as noted in the methods, mutation rates in woody plants are thought to be slower-not faster-than the one applied here, so a LGM divergence is extremely unlikely.

\section{DISCUSSION}

The genomic distinctiveness of the $\mathrm{CC}$ populations from the disjunct AS and lack of any regional structure that group populations from the two regions indicate the Amazonian populations have evolved independently (for the most part) from the Cerrado. As such, it is isolation and not recent connections (either via long-distance dispersal or expansion/retraction via corridors) that dominates in this tropical biome; substantial admixture was limited to a single population that borders the Cerrado (see also Buzatti, Lemos, Bueno, \& Lovato, 2017 for localized study of another plant species from this focal area). The extent to which these results are generalizable to other taxa from the Cerrado and Amazonian savannas is discussed below, as is what our results suggest about the evolutionary dynamics of relictual populations in tropical systems. In both discussions, we advocate for a more nuanced approach to tests of the relative isolation versus connections of AS populations. In addition, with reference to our own results, we highlight how some refined hypotheses might provide more insight about why one process might predominate over the other in particular taxa or geographic regions. Lastly,

TABLE 2 Divergence time estimates (assuming a minimum of a 3 year generation time; see methods for details) and other demographic parameters for each Byrsonima species based on the model of divergence between the Amazonian savannas (AS) and central Cerrado (CC) regions using FASTSIMCOAL2. Specifically, we show results for divergence time, $T_{D I V}$, ancestral effective population size, $N_{\text {ANC, }}$ effective population size for $A S, N_{A S}$, and number of loci used to calculate the folded joint site frequency spectrum (SFS). Confidence intervals based on 100 parametric boostraps are shown in parentheses. Note that effective population size of the CC ( $\left.N_{C C}\right)$ was calculated directly from the empirical data (i.e., was a fixed parameter in the model) to improve the accuracy of the other parameters estimated from the SFS (following the recommendations for the program; see Excoffier \& Foll, 2011)

\begin{tabular}{llllll}
\hline Species & Loci & $T_{\text {DIV }}$ (years) & $N_{\text {ANC }}$ & $N_{\text {CC }}$ & $N_{\text {AS }}$ \\
\hline $\begin{array}{l}\text { Byrsonima coccolobifolia (all populations) } \\
\begin{array}{l}\text { Byrsonima coccolobifolia (excluding } \\
\text { admixed populations A-coHTA, }\end{array}\end{array}$ & 2285 & $109,611(87,432-143,886)$ & $100,400(60,069-176,369)$ & 978,571 & $343,875(263,662-502,760)$ \\
$\begin{array}{l}\text { coCHG and coVHA) } \\
\text { Byrsonima crassifolia }\end{array}$ & $119,379(96,195-169,311)$ & $56,282(31,697-102,681)$ & 992,857 & $210,635(162,674-322,062)$ \\
\hline
\end{tabular}


given the general lack of phylogeographic studies of the AS, we reflect on the relevance of our results on the processes contributing to savanna species diversity, as well as to future conservation efforts.

\subsection{Past connections versus isolation of Amazonian savannas}

To explain the similarity between CC and AS, three regional connections or corridors were proposed: the coastal, the central Amazonian, and the Andean corridor (Haffer, 1967, 1974; Silva \& Bates, 2002; Webb, 1991). These corridors are hypothesized to have connected the CC and AS during waves of Pleistocene savanna expansions (Haffer, 1969; Silva \& Bates, 2002), possibly as recent as the Holocene (see de Freitas et al., 2001). However, our genomic data did not provide strong support for the existence of such corridors in either species. Instead, analyses suggest a history of restricted gene flow between the CC and AS (Figure 4), with the AS evolving in relative isolation from the $\mathrm{CC}$ over a history of divergence that predates the LGM (Table 2). This is corroborated by palynological evidence that draws into question any recent large savanna expansions that might have served as connections between the CC and AS (Colinvaux, Oliveira, Moreno, Miller, \& Bush, 1996; Colinvaux et al., 2001; Kastner \& Goni, 2003; Mayle et al., 2009). The only exception is the admixture detected in one south-western Amazon population (see Figure 4), which is a region where joint analyses of ENMs and cpDNA data in an unrelated plant also found evidence of a connection to the CC (see Buzatti et al., 2017; note this study focused only on this single site so it is not possible to determine if other AS populations in the species remained isolated from the CC).

The independent evolutionary history of CC and AS has important implications for questions beyond those focused on genetic structure per se. Although Byrsonima species are suggested to display effective long-distance dispersal (Willis, Franzone, Xi, \& Davis, 2014), there is no clear evidence of recent gene flow in B. coccolobifolia and B. crassifolia, indicating that long-distance dispersal is not common. The genetic isolation of CC from AS (Figure 5), in addition to the compositional similarities in their constituent plant communities (with over 70 woody species in common; Ratter et al., 2003) suggests a more ancient common history, rather than the maintenance by corridors per se. Moreover, it implies that the differences in species composition between the AS and CC might reflect the cumulative loss of species in the AS (community relaxation-Connor \& McCoy, 1979), rather than differences in the maintenance of diversity through successful/unsuccessful utilization of corridors. Additional circumstantial evidence of localized extinctions rests in the observation that few Cerrado taxa are found across all AS populations (Ratter et al., 2003). Alternatively, with many taxa restricted in distribution to the $\mathrm{CC}$, there might have been historical restrictions to expansion for many taxa such that they were never part of the AS, even when Cerrado reached its broadest historical distribution. Additional tests will be needed to evaluate this hypothesis. These might include testing for evidence of environmental filtering or differences in the dispersal capabilities of exclusively CC taxa compared with those distributed across the AS, although no significant difference in seed dispersal syndromes for species present in $\mathrm{CC}$ and AS has been suggested in past studies (see Vieira, Aquino, Brito, Fernandes-Bulhão, \& Henriques, 2002).

\subsection{Conflicting support for connections of the CC and AS}

When comparing our results to past studies purported to support hypothesized connections between the CC and AS, several nonmutually exclusive explanations might account for such contrasting support of the corridor hypothesis. These include: (a) differences in the resolution of genetic markers, (b) relying solely upon applications of distributional or ecological-niche models, and (c) differences among taxa in access to the corridors due to historical contingencies or differences in the taxa themselves (i.e., speciesspecific traits). Below, we consider each of these explanations in turn with reference to results from our analyses of B. coccolobifolia and B. crassifolia.

The genetic marker applied to test a phylogeographic hypothesis can impact the likelihood that a study might find support for or refute a particular hypothesis (Knowles, 2009). In particular, tests that rely upon genetic structure as evidence of isolation (e.g., when support for putative corridors is based on the lack of genetic differentiation between CC and AS regions; Savit \& Bates, 2015) may be obscured by limited genetic resolution, including an insufficient time for the sorting of ancestral polymorphism or the lack of mutation variation for detecting historical divisions (Ball, Neigel, \& Avise, 1990; Papadopoulou \& Knowles, 2015; Thomaz et al., 2017). For example, sharing of chloroplast haplotypes between CC and AS populations in B. coccolobifolia and B. crassifolia (Figure 3) could suggest recent gene flow or connections, as might the lack of regional cpDNA clades separating the CC and AS regions (Figure S2.1 in Appendix S2). However, analysis of genomic data clearly shows that $\mathrm{CC}$ and AS regions are genetically distinct in both species (Figure 4). In other words, if chloroplast data by itself are going to be used to refute a hypothesis of isolation, it is important to test whether the data may be consistent with a history of isolation, which can be evaluated using computer simulations (see Knowles \& Maddison, 2002). Alternatively, and as we apply here, additional markers can be used to model the divergence history of the species (as opposed to the history of a single locus; see Knowles, 2009). Here, the parameterized divergence models support a long history of isolation between CC and AS regions that predate the LGM (Table 2).

For the Cerrado, evidence for the existence of corridors connecting areas north and south of Amazon comes primarily from distributional data (e.g., Ávila-Pires, 1995; Nogueira \& Rodrigues, 2006; Silva $\&$ Bates, 2002), with some support for distinct routes of movement suggested by a few phylogeographic studies (e.g., Buzatti et al., 2017; Quijada-Mascareñas et al., 2007; Savit \& Bates, 2015). As with concerns regarding inferences based on a single locus, inferences based on ENMs alone might also be misleading (as opposed to 
considering ENMs jointly with molecular data; reviewed in AlvaradoSerrano \& Knowles, 2014). Specifically, although ENMs might be used to identify possible connections, without genetic data, it is not possible to test whether species actually utilized purported corridors (i.e., gene flow might not have been associated with the corridors inferred from ENMs for many of the different reasons discussed above). Here, we advocate that, as with the interpretation of single locus data, extreme caution is needed. More specifically, studies based solely on ENMs should be used to generate hypotheses, but do not (by themselves) constitute evidence for supporting the corridors hypothesis.

Assuming that such corridors existed, it is possible that some species just by chance, found themselves in the right place at the right time to have access to a corridor, whereas others did not. On the other hand, the lack of consistent support for corridors could also reflect deterministic processes related to species-specific differences (Massatti \& Knowles, 2014, 2016; Papadopoulou \& Knowles, 2016). Indeed, the organisms investigated in the phylogeographic studies that sampled broadly the AS include different taxonomic groups (e.g., birds, snakes, and this study with plants) with distinct dispersal abilities and the distribution of some investigated taxa is not restricted to the savannas (e.g., Savit \& Bates, 2015). Although it is possible that $B$. coccolobifolia and $B$. crassifolia differ from taxa for which future genomic analyses might show corridors between the CC and AS regions, it is not obvious why B. coccolobifolia and $B$. crassifolia would not have utilized corridors (if they existed). First, they are very common species and widely distributed (Figure 1), so unlike rare or patchily distributed species, they most probably would have had access to any putative corridor. Second, these attributes also make it less likely that any species-specific traits would have restricted their movement (i.e., they obviously can readily disperse to occupy vast areas of the Cerrado biome).

\subsection{Scale-specific effects of climate-induced distributional shifts}

As possible remnants of a dynamic historical past, the tropical Amazonian savannas are similar to relict populations in northern latitudes (Pielou, 1991). However, this dynamic history, with cycles of climateinduced distributional shifts, contributes to the enigmatic nature of tropical relicts and debate over their role as drivers of divergence (e.g., Capurucho et al., 2013). By rejecting hypothesized periods of connectivity between CC and AS through putative expansions during glacial-interglacial periods (Prance, 1996; Silva \& Bates, 2002), our study raises some intriguing questions about divergence of Cerrado species. Here, we make the argument that connections forged during cycles of expansion, while not extensive enough to support corridors between the CC and AS, may have played an important role in divergence within the CC and within the AS. In other words, geographic scale determines whether climatic oscillations promote connections. Likewise, we note that the existence of regional structure itself within both the CC and AS, suggests a limit on the level of connectiveness across populations in the past (otherwise, the regional structure would have been lost, and the only structure would be the population level structure that was also observed; see Figure 5).

What might limit the role of climate-induced distributional shifts at the larger scale- - that is, why were distributional shifts not associated with connections between the CC and the AS? The most obvious answer is that the extent of savanna expansion (or conversely forest contraction) may have been more limited than previous proposals. For example, suggestions of a fairly stable forest during the LGM, especially for the western part of Amazon (e.g., Bush, Silman, \& Urrego, 2004; Cheng et al., 2013; Colinvaux, Oliveira, \& Bush, 2000), offer an alternative to Haffer's (1969) scenario of forest fragmentation during glacial periods. In addition, recent isotopic data sampled from the Amazon dry corridor (i.e., an area of current lower precipitation within the Amazon, Haffer, 1969) suggest forest physiognomies during the LGM consistent with the maintenance of rain forest (Wang et al., 2017), and/or its replacement by dry-forest habitats, instead of savanna (Bush, 2017; Pennington, Prado, \& Pendry, 2000).

Within the CC, past phylogeographic studies of plants have documented an east-west split that is generally concordant with Byrsonima (Figure 6c,d) (reviewed in Leal, Palma-Silva, \& Pinheiro, 2016). Likewise, a regional genetic structuring of individuals sampled in southern, central-northern and north-western portions of Cerrado has been observed in other organisms, including frogs and lizards (Prado, Haddad, \& Zamudio, 2012; Santos, Nogueira, Giugliano, \& Colli, 2014). This spatial concordance across studies highlights how these CC communities may be shaped by similar historical processes. Similarly, among the AS populations, regional divergence is clear, as is differentiation among individual populations (Figures 5 and 6). However, it is not clear what accounts for the observed regional structure of AS populations of both Byrsonima species because unfortunately, unlike the $\mathrm{CC}$, there are extremely limited data in terms of genetic analyses of broadly sampled AS populations (in fact, we are not aware of any other studies besides ours). We note that in other types of open habitat (e.g., birds inhabiting white sand vegetation), genetic data provide evidence of recent population expansion during the late Pleistocene (Capurucho et al., 2013; Matos et al., 2016), suggesting that the connections we propose among AS populations based on regional structuring of genetic variation may not be an anomaly. It is clear that future research will be charting new directions about the drivers of divergence within the $\mathrm{CC}$ and $\mathrm{AS}$ as the focus shifts from one built on a history of corridors connections, to the independent evolutionary trajectories of the CC and AS.

\subsection{Conservation of Cerrado and Amazonian savannas}

Despite the high endemism and species diversity, the Cerrado is rapidly being loss (less than $20 \%$ remains undisturbed; Strassburg et al., 2017), especially with the expansion of agriculture, cattle ranching, and charcoal production, and conservation of the Cerrado biome has received little attention. Although rates of loss have decreased over the last several years (i.e., since 2010), we are nevertheless loosing Cerrado faster than Amazon Forest (Françoso et al., 2015). 
Given the extent of the biome, covering 2 million $\mathrm{km}^{2}$, assessments of genetic diversity and population structure arguably could provide important guidance in conservation efforts. Yet, with relatively sparse geographic sampling, and limited genomic study, such information is rarely considered in conserving this highly threatened biome. Analyses of broadly distributed taxa in particular, like B. coccolobifolia and $B$. crassifolia, could be used to devise conservation strategies that protect not only the constituent taxa, but also preserve diversity generating processes (see Moritz, 2002). For example, our study revealed an unexpected cryptic species in B. coccolobifolia from the central and northern areas of the CC, an area reportedly of high species richness (Ratter et al., 2003). Other phylogeographic studies on Cerrado trees suggest the highest genetic diversity occurs in central areas of the Cerrado as well (e.g., Collevatti, Castro, Lima, \& Telles, 2012; Novaes, Lemos-Filho, Ribeiro, \& Lovato, 2010; Souza, Collevatti, Lima-Ribeiro, Lemos-Filho, \& Lovato, 2017); however, many of these have limited sampling of northern areas. Our results, as those with more extensive sampling (Collevatti, Terribile, Diniz, \& Lima-Ribeiro, 2015; Ribeiro, Lemos, Buzatti, Lovato, \& Heuertz, 2016) have revealed high genetic diversity in north-eastern plant populations, highlighting the importance of these areas to conservation efforts of the Cerrado, especially since these areas are part of an expanding agricultural frontier.

Perhaps most importantly, our broad sampling of plant species from the AS identifies a number of factors relevant to developing conservation priorities for the AS. First, we show that these populations display levels of genetic diversity similar to CC populations, which is somewhat reassuring about their general health from a genetic prospective (i.e., they do not show disproportionately depressed levels of diversity; see Figure 3 and Table 1). However, their apparent genetic isolation does place them at substantial risk (Figure 4). Moreover, these populations arguably should be considered as unique Cerrado environments in conservation efforts of the biome, given their relatively long isolated history from the $\mathrm{CC}$ (see Table 2). Even though most AS display much less species diversity than the CC (but see Ratter et al., 2003 for exceptions), some AS contain more than 250 plant taxa (Miranda, Absy, \& Rebelo, 2003; Sanaiotti, 1997), in addition to vulnerable and endemic species of birds, reptiles, amphibians, and plants (Barbosa, Campos, Pinto, \& Fearnside, 2007; Carvalho, 1997; França, Mesquita, \& Colli, 2006; Rocha \& Miranda, 2014). It is also important to note that the number of species in the AS most likely is larger considering that these areas are highly understudied (Carvalho \& Mustin, 2017). Lastly, AS are under particularly high anthropogenic disturbance because they are misleadingly considered as natural pastures in an environment largely dominated by forest (Miranda et al., 2003), making immediate attention as conservation units an imperative (Carvalho \& Mustin, 2017).

\section{5 | CONCLUSIONS}

Our results show independent evolution of the $\mathrm{CC}$ and AS populations of both broadly distributed tree species studied here (B. coccolobifolia and $B$. crassifolia), casting doubt on the importance of corridors in structuring Cerrado plant communities. In the context of understanding the evolutionary history of AS populations in particular, it is possible that climatic change in the tropics, and/or differences in the traits of the species themselves, might make certain corridors more or less accessible during different geologic periods (Silva \& Bates, 2002; Wüster et al., 2005), but careful consideration of this hypothesis will require expanding the dataset to other broadly distributed taxa. Specifically, our genomic data suggest a relatively long history of isolation between the CC and AS regions that predates the LGM, as well as population structuring of genetic variation within regions in both species. The contrast between genetic structure of genomic versus chloroplast datasets also highlights the need for cautious interpretation of what constitutes evidence for the corridor hypothesis. Our findings suggest that methodology, not biology, may contribute to some of the differences in support for the corridor hypothesis reported across studies. Lastly, as a biodiversity hotspot, these results have direct implications for diversification in the Cerrado, as well as its conservation, especially given extensive and ongoing habitat destruction (Carvalho \& Mustin, 2017; Mittermeier et al., 2004).

\section{ACKNOWLEDGEMENTS}

The authors thank the Instituto Chico Mendes de Conservação da Biodiversidade (ICMBio), for providing sampling permits, and the Instituto Nacional de Ciência e Tecnologia Herbário Virtual da Flora e dos Fungos (INCT-HVFF, funded by Conselho Nacional de Desenvolvimento Científico e Tecnológico-CNPq) and Ary Oliveira-Filho for compiling information regarding species occurrence. We are especially thankful to taxonomists Maria Candida Mamede and Augusto Francener from Instituto de Botânica for help with species identification. We also thank for all assistance for sampling AS populations: Hugo Alencar from Instituto Brasileiro do Meio Ambiente e dos Recursos Naturais Renováveis (IBAMA) in Vilhena/ RO, Cláudia Lima from ICMBio in Porto Velho/RO, Marcelo Carvalho and Bruno Souza from ICMBio in Boa Vista/RR, Adilson Lopes and Rogério Alves from Embrapa Macapá/AP. We are grateful to Anna Papadopoulou for helpful discussion of analyses and processing of ddRADseq data. Funding was provided for field work and genetic analysis by Fundação de Amparo à Pesquisa do Estado de Minas Gerais (FAPEMIG) and CNPq. This research was also partially supported by funds to LLK from the University of Michigan, Ann Arbor. LCRM received a PhD scholarship from the Brazilian Federal Agency for Support and Evaluation of Graduate Education within the Ministry of Education of Brazil (CAPES PDSE 99999.003882/2015-02), and MBL and JPLF received research fellowships from CNPq.

\section{ORCID}

Luciana C. Resende-Moreira (iD http://orcid.org/0000-0003-29778433

Andréa T. Thomaz iD https://orcid.org/0000-0002-9755-2674

Joyce R. Prado iD http://orcid.org/0000-0002-2025-5479 


\section{REFERENCES}

Alvarado-Serrano, D. F., \& Knowles, L. L. (2014). Ecological niche models in phylogeographic studies: Applications, advances and precautions. Molecular Ecology Resources, 14, 233-248. https://doi.org/10.1111/ 1755-0998.12184

Anderson, W. R. (1981). Malpighiaceae, The Botany of the Guayana Highland, Part XI, vol. 32. Memoirs of the New York Botanical Garden, 32, 21-305.

Anderson, W. R. (1983). Byrsonima crassifolia (Nance, Nancite, Shoemaker's Tree). In D. H. Janzen (Ed.), Costa Rican natural history (pp. 202-204). Chicago, IL: University Chicago Press.

Anderson, W. R., Anderson, C., \& Davis, C. C. (2006). Malpighiaceae. http://herbarium.lsa.umich.edu/malpigh/index.html Accessed on: 01 May 2017.

Ávila-Pires, T. C. S. (1995). Lizards of Brazilian Amazonia (Reptilia: Squamata). Zoologische Verhandelingen, 299, 1-706.

Avise, J. C. (2004). Molecular markers, natural history and evolution, 2nd ed.. Sunderland, MA: Sinauer Associates.

Ball, R. M., Neigel, J. E., \& Avise, J. C. (1990). Gene genealogies within the organismal pedigrees of random-mating populations. Evolution, 44, 360-370. https://doi.org/10.1111/j.1558-5646.1990.tb05205.x

Barbosa, R. I., Campos, C., Pinto, F., \& Fearnside, P. M. (2007). The "Lavrados" of Roraima: biodiversity and conservation of Brazil's Amazonian savannas. Functional Ecosystems \& Communities, 1, 29-41.

Behling, H., \& Hooghiemstra, H. (2001). Neotropical savanna environments in space and time: Late Quaternary inter-hemispheric comparisons. In V. Markgraf (Ed.), Interhemispheric climate linkages (pp. 307-323). San Diego, CA: Academic Press. https://doi.org/10. 1016/B978-012472670-3/50021-5

Benezar, R. M., \& Pessoni, L. A. (2006). Floral biology and the reproductive system of Byrsonima coccolobifolia (Kunth) in an Amazonian savanna. Acta Amazonica, 36, 159-68. https://doi.org/10.1590/ S0044-59672006000200005

Bonatelli, I. A. S., Perez, M. F., Peterson, A. T., Taylor, N. P., Zappi, D. C., Machado, M. C., \& Moraes, E. M. (2014). Interglacial microrefugia and diversification of a cactus species complex: Phylogeography and palaeodistributional reconstructions for Pilosocereus aurisetus and allies. Molecular Ecology, 23, 3044-3063. https://doi.org/10.1111/mec.12780

Bueno, M. L., Pennington, R. T., Dexter, K. G., Kamino, L. H. Y., Pontara, V., Neves, D. M., \& Oliveira-Filho, A. T. (2017). Effects of Quaternary climatic fluctuations on the distribution of Neotropical savanna tree species. Ecography, 40, 403-414. https://doi.org/10.1111/ecog.01860

Buerkle, C. A., \& Gompert, Z. (2013). Population genomics based on low coverage sequencing: How low should we go? Molecular Ecology, 22, 3028-3035. https://doi.org/10.1111/mec.12105

Bush, M. B. (2017). The resilience of Amazonian forests. Nature, 541, 167-168. https://doi.org/10.1038/541167a

Bush, M. B., Silman, M. R., \& Urrego, D. H. (2004). 48,000 years of climate and forest change in a biodiversity hotspot. Science, 303, 827829. https://doi.org/10.1126/science.1090795

Buzatti, R. S. D., Lemos, J. P., Bueno, M. L., \& Lovato, M. B. (2017). Multiple Pleistocene refugia in the Brazilian cerrado: Evidence from phylogeography and climatic nichemodelling of two Qualea species (Vochysiaceae). Botanical Journal of the Linnean Society, 185, 307320. https://doi.org/10.1093/botlinnean/box062

Capurucho, J. M. G., Cornelius, C., Borges, S. H., Cohn-Haft, M., Aleixo, A., Metzger, J. P., \& Ribas, C. C. (2013). Combining phylogeography and landscape genetics of Xenopipo atronitens (Aves: Pipridae), a white sand campina specialist, to understand Pleistocene landscape evolution in Amazonia. Biological Journal of the Linnean Society, 110, 60-76. https://doi.org/10.1111/bij.12102

Carvalho, A. M. (1997). A synopsis of the genus Dalbergia (Fabaceae: Dalbergieae) in Brazil. Brittonia, 49, 87-109. https://doi.org/10.2307/ 2807701
Carvalho, W. D., \& Mustin, K. (2017). The highly threatened and little known Amazonian savannahs. Nature Ecology \& Evolution, 1, 100. https://doi.org/10.1038/s41559-017-0100

Catchen, J., Hohenlohe, P. A., Bassham, S., Amores, A., \& Cresko, W. A. (2013). Stacks: An analysis tool set for population genomics. Molecular Ecology, 22, 3124-3140. https://doi.org/10.1111/mec.12354

Cheng, H., Sinha, A., Cruz, F. W., Wang, X. F., Edwards, R. L. A., d'Horta, F. M., \& Auler, A. S. (2013). Climate change patterns in Amazonia and biodiversity. Nature Communications, 4, 1411. https://doi.org/10. 1038/ncomms2415

Colinvaux, P. A., Irion, G., Rasanen, M. E., Bush, M. B., \& de Mello, J. (2001). A paradigm to be discarded: Geological and paleoecological data falsify the Haffer \& Prance refuge hypothesis of Amazonian speciation. Amazoniana, 16, 609-646.

Colinvaux, P. A., Oliveira, P. E., \& Bush, M. B. (2000). Amazonian and neotropical plant communities on glacial time-scales: The failure of the aridity and refuge hypotheses. Quaternary Science Reviews, 19, 141-169. https://doi.org/10.1016/S0277-3791(99)00059-1

Colinvaux, P. A., Oliveira, P. E., Moreno, J. E., Miller, M. C., \& Bush, M. B. (1996). A long pollen record from lowland Amazonia: Forest and cooling in glacial times. Science, 274, 85-88. https://doi.org/10. 1126/science.274.5284.85

Collevatti, R. G., Castro, T. G., Lima, J. S., \& Telles, M. C. (2012). Phylogeography of Tibouchina papyrus (Pohl) Toledo (Melastomataceae), an endangered tree species from rocky savannas, suggests bidirectional expansion due to climate cooling in the Pleistocene. Ecology and Evolution, 2, 1024-1035. https://doi.org/10.1002/ece3.236

Collevatti, R. G., Terribile, L. C., Diniz-Filho, J. A. F., \& Lima-Ribeiro, M. S. (2015). Multi-model inference in comparative phylogeography: An integrative approach based on multiple lines of evidence. Frontiers in Genetics, 6, 31.

Collevatti, R. G., Terribile, L. C., Rabelo, S. G., \& Lima-Ribeiro, M. S (2015). Relaxed random walk model coupled with ecological niche modeling unravel the dispersal dynamics of a Neotropical savanna tree species in the deeper Quaternary. Frontiers in Plant Sciences, 6, 653.

Connor, E. F., \& McCoy, E. D. (1979). Statistics and biology of the species-area relationship. American Naturalist, 113, 791-833. https://doi. org/10.1086/283438

de Freitas, H. A., Pessenda, L. C. R., Aravena, R., Gouveia, S. E. M. Ribeiro, A. D., \& Boulet, R. (2001). Late Quaternary vegetation dynamics in the southern Amazon basin inferred from carbon isotopes in soil organic matter. Quaternary Research, 55(1), 39-46. https://doi.org/10.1006/qres.2000.2192

de Lima, N. E., Lima-Ribeiro, M. S., Tinoco, C. F., Terribile, L. C., \& Collevatti, R. G. (2014). Phylogeography and ecological niche modelling, coupled with the fossil pollen record, unravel the demographic history of a Neotropical swamp palm through the Quaternary. Journal of Biogeography, 41, 673-686. https://doi.org/ 10.1111/jbi.12269

Demesure, B., Sodzi, N., \& Petit, R. J. (1995). A set of universal primers for amplification of polymorphic non-coding regions of mitochondrial and chloroplast DNA in plants. Molecular Ecology, 4, 129-131. https://doi.org/10.1111/j.1365-294X.1995.tb00201.x

Dray, S., \& Dufour, A. B. (2007). The ade4 package: Implementing the duality diagram for ecologists. Journal of Statistical Software, 22, 120.

Earl, D. A., \& Vonholdt, B. M. (2012). STRUCTURE HARVESTER: A website and program for visualizing STRUCTURE output and implementing the Evanno method. Conservation Genetics Resources, 4, 359-361. https://doi.org/10.1007/s12686-011-9548-7

Excoffier, L., Dupanloup, I., Huerta-Sánchez, E., Sousa, V. C., \& Foll, M. (2013). Robust demographic inference from genomic and SNP data. Plos Genetics, 9, e1003905. https://doi.org/10.1371/journal.pgen. 1003905 
Excoffier, L., \& Foll, M. (2011). Fastsimcoal: A continuous-time coalescent simulator of genomic diversity under arbitrarily complex evolutionary scenarios. Bioinformatics, 27, 1332-1334. https://doi.org/10.1093/ bioinformatics/btr124

França, F. G. R., Mesquita, D. O., \& Colli, G. R. (2006). A checklist of snakes from Amazonian savannas in Brazil, housed in the Coleção Herpetológica da Universidade de Brasília, with new distribution records. Occasional Papers Oklahoma Museum of Natural History, 17, $1-13$.

Françoso, R. D., Brandão, R., Nogueira, C. C., Salmona, Y. B., Machado, R. B., \& Colli, G. R. (2015). Habitat loss and the effectiveness of protected areas in the Cerrado biodiversity hotspot. Natureza \& Conservação, 13, 35-40. https://doi.org/10.1016/j.ncon.2015.04.001

Haffer, J. (1967). Zoogeographical notes on the "nonforest" lowland bird faunas of northwestern South America. Hornero, 10, 315-333.

Haffer, J. (1969). Speciation in Amazonian Forest Birds. Science, 165, 131-137. https://doi.org/10.1126/science.165.3889.131

Haffer, J. (1974). Avian speciation in tropical South America, with a systematic survey of the toucans (Ramphastidae) and jacamars (Galbulidae). Nuttall Orthological Club, 14, 1-390.

Hamilton, M. B. (1999). Four primer pairs for the amplification of chloroplast intergenic regions with intraspecific variation. Molecular Ecology, $8,521-523$

Hewitt, G. M. (2004). Genetic consequences of climatic oscillations in the Quaternary. Philosophical Transactions of the Royal Society of London Series B-Biological Sciences, 359, 183-195. https://doi.org/10.1098/ rstb.2003.1388

Huang, H. T., \& Knowles, L. L. (2016). Unforeseen consequences of excluding missing data from next-generation sequences: Simulation study of RAD sequences. Systematic Biology, 65, 357-365. https://d oi.org/10.1093/sysbio/syu046

Jaramillo, C., Hoorn, C., Silva, S. A. F., Leite, F., Herrera, F., Quiroz, L., \& Antonioli, L. (2010). The origin of the modern Amazon rainforest: Implications of the palynological and palaeobotanical record. In C. Hoorn, \& F. P. Wesselingh (Eds.), Amazonia: Landscape and species evolution: A look into the past (pp. 317-334). Hoboken, NJ: WileyBlackwell.

Jombart, T. (2008). adegenet: A R package for the multivariate analysis of genetic markers. Bioinformatics, 24, 1403-1405. https://doi.org/ 10.1093/bioinformatics/btn129

Jombart, T., \& Ahmed, I. (2011). adegenet 1.3-1: New tools for the analysis of genome-wide SNP data. Bioinformatics, 27, 3070-3071. https://doi.org/10.1093/bioinformatics/btr521

Jombart, T., Pontier, D., \& Dufour, A. B. (2009). Genetic markers in the playground of multivariate analysis. Heredity, 102, 330-341. https://d oi.org/10.1038/hdy.2008.130

Kastner, T. P., \& Goni, M. A. (2003). Constancy in the vegetation of the Amazon basin during the late Pleistocene: Evidence from the organic matter composition of Amazon deep sea fan sediments. Geology, 31 291-294. https://doi.org/10.1130/0091-7613(2003)031\&lt;0291:CIT VOT\&gt;2.0.CO;2

Knowles, L. L. (2009). Statistical phylogeography. Annual Review of Ecology Evolution and Systematics, 40, 593-612. https://doi.org/10.1146/ annurev.ecolsys.38.091206.095702

Knowles, L. L., \& Maddison, W. P. (2002). Statistical phylogeography. Molecular Ecology, 11, 2623-2635. https://doi.org/10.1046/j.1365294X.2002.01637.x

Knowles, L. L., \& Massatti, R. (2017). Distributional shifts-Not geographic isolation-As a probable driver of montane species divergence. Ecography, 40, 1475-1485. https://doi.org/10.1111/ecog. 02893

Kopelman, N. M., Mayzel, J., Jakobsson, M., Rosenberg, N. A., \& Mayrose, I. (2015). Clumpak: A program for identifying clustering modes and packaging population structure inferences across K. Molecular
Ecology Resources, 15, 1179-1191. https://doi.org/10.1111/17550998.12387

Leal, B. S. S., Palma-Silva, C., \& Pinheiro, F. (2016). Phylogeographic studies depict the role of space and time scales of plant speciation in a highly diverse neotropical region. Critical Reviews in Plant Sciences, 35, 215-230. https://doi.org/10.1080/07352689.2016.1254494

Ledru, M. P. (2002). Late Quaternary history and evolution of the cerrados as revealed by palynological records. In P. S. Oliveira, \& R. J. Marquis (Eds.), The Cerrados of Brazil: Ecology and natural history of a Neotropical savanna (pp. 33-50). New York, NY: Columbia University Press.

Librado, P., \& Rozas, J. (2009). DnaSP v5: A software for comprehensive analysis of DNA polymorphism data. Bioinformatics, 25, 1451-1452. https://doi.org/10.1093/bioinformatics/btp187

Massatti, R., \& Knowles, L. L. (2014). Microhabitat differences impact phytogeographic concordance of codistributed species: Genomic evidence in montane sedges (Carex L.) from the Rocky Mountains. Evolution, 68, 2833-2846. https://doi.org/10.1111/evo.12491

Massatti, R., \& Knowles, L. L. (2016). Contrasting support for alternative models of genomic variation based on microhabitat preference: Species-specific effects of climate change in alpine sedges. Molecular Ecology, 25, 3974-3986. https://doi.org/10.1111/mec.13735

Matos, M. V., Borges, S. H., d'Horta, F. M., Cornelius, C., Latrubesse, E., Cohn-Haft, M., \& Ribas, C. C. (2016). Comparative phylogeography of two bird species, Tachyphonus phoenicius (Thraupidae) and Polytmus theresiae (Trochilidae), specialized in Amazonian white-sand vegetation. Biotropica, 48, 1.

Mayle, F. E., Burn, M. J., Power, M., \& Urrego, D. H. (2009). Vegetation and fire at the Last Glacial Maximum in Tropical South America. In F. Vimeux, F. Sylvestre, \& M. Khodri (Eds.), Past climate variability in South America and surrounding regions (pp. 89-112). Dordrecht, Netherlands: Springer. https://doi.org/10.1007/978-90-481-2672-9

Migliore, J., Baumel, A., Juin, M., Fady, B., Roig, A., Duong, N., \& Medail, F. (2013). Surviving in mountain climate refugia: New insights from the genetic diversity and structure of the relict shrub Myrtus nivellei (Myrtaceae) in the Sahara desert. PLoS ONE, 8, e73795. https://doi. org/10.1371/journal.pone.0073795

Miranda, I. S., Absy, M. L., \& Rebelo, G. H. (2003). Community structure of woody plants of Roraima Savannahs, Brazil. Plant Ecology, 164, 109-123. https://doi.org/10.1023/A:1021298328048

Mittermeier, R. A., Gil, P. R., Hoffman, M., Pilgrim, J., Brooks, T., Mittermeier, C. G., \& Fonseca, G. A. B. (2004). Hotspots revisited: Earth's biologically richest and most threatened terrestrial ecoregions. Mexico City: CEMEX

Moritz, C. (2002). Strategies to protect biological diversity and the evolutionary processes that sustain it. Systematic Biology, 51, 238-254. https://doi.org/10.1080/10635150252899752

Nogueira, C., \& Rodrigues, M. T. (2006). The genus Stenocercus (Squamata: Tropiduridae) in extra-Amazonian Brazil, with the description of two new species. South American Journal of Herpetology, 12, 149165. https://doi.org/10.2994/1808-9798(2006)1[149:TGSSTI]2.0. $\mathrm{CO} ; 2$

Novaes, R. M. L., Lemos-Filho, J. P., Ribeiro, R. A., \& Lovato, M. B. (2010). Phylogeography of Plathymenia reticulata (Leguminosae) reveals patterns of recent range expansion towards northeastern Brazil and southern Cerrados in Eastern Tropical South America. Molecular Ecology, 19, 985-998. https://doi.org/10.1111/j.1365-294X.2010. 04530.x

Novaes, R. M. L., Rodrigues, J. G., \& Lovato, M. B. (2009). An efficient protocol for tissue sampling and DNA isolation from the stem bark of Leguminosae trees. Genetics and Molecular Research, 8, 86-96. https://doi.org/10.4238/vol8-1gmr542

Oksanen, J., Blanchet, F. G., Friendly, M., Kinda, R., Legendre, P., McGlinn, D., ... Wagner, H. (2017). vegan: Community Ecology 
Package (Version 2.4-4). R package. Retrieved from https://CRAN.Rproject.org/package=vegan. Accessed 2017-07-06.

Oliveira-Filho, A. T. (2017). NeoTropTree, flora arbórea da região Neotropical: um banco de dados envolvendo biogeografia, diversidade e conservação. Retrieved from http://www.icb.ufmg.br/treeatla n. Accessed 2017-01-06.

Ornelas, J. F., Ruiz-Sanchez, E., \& Sosa, V. (2010). Phylogeography of Podocarpus matudae (Podocarpaceae): Pre-Quaternary relicts in northern Mesoamerican cloud forests. Journal of Biogeography, 37, 2384 2396. https://doi.org/10.1111/j.1365-2699.2010.02372.x

Ossowski, S., Schneeberger, K., Lucas-Lledo, J. I., Warthmann, N., Clark, R. M., Shaw, R. G., \& Lynch, M. (2010). The rate and molecular spectrum of spontaneous mutations in Arabidopsis thaliana. Science, 327, 92-94. https://doi.org/10.1126/science.1180677

Papadopoulou, A., \& Knowles, L. L. (2015). Genomic tests of the speciespump hypothesis: Recent island connectivity cycles drive population divergence but not speciation in Caribbean crickets across the Virgin Islands. Evolution, 69, 1501-1517. https://doi.org/10.1111/evo.12667

Papadopoulou, A., \& Knowles, L. L. (2016). Toward a paradigm shift in comparative phylogeography driven by trait-based hypotheses. Proceedings of the National Academy of Sciences of the United States of America, 113, 8018-8024. https://doi.org/10.1073/pnas.1601069113

Pascual, R., \& Jaureguizar, E. O. (1990). Evolving climates and mammal faunas in Cenozoic South-America. Journal of Human Evolution, 19, 23-60. https://doi.org/10.1016/0047-2484(90)90011-Y

Pennington, R. T., Lewis, G. P., \& Ratter, J. A. (2006). An overview of the plant diversity, biogeography and conservation of Neotropical savannas and seasonally dry forests. In R. T. Pennington, G. P. Lewis, \& J. A. Ratter (Eds.), Neotropical savannas and seasonally dry forests: Plant diversity, biogeography, and conservation (pp. 1-30). Boca Raton, FL: Taylor \& Francis Group. https://doi.org/10.1201/CRCSYSASSSPE

Pennington, R. T., Prado, D. E., \& Pendry, C. A. (2000). Neotropical seasonally dry forests and Quaternary vegetation changes. Journal of Biogeography, 27, 261-273. https://doi.org/10.1046/j.1365-2699.2000. 00397.x

Peterson, B. K., Weber, J. N., Kay, E. H., Fisher, H. S., \& Hoekstra, H. E. (2012). Double digest RADseq: An inexpensive method for de novo SNP discovery and genotyping in model and non-model species. PLoS ONE, 7, e37135. https://doi.org/10.1371/journal.pone.0037135

Pielou, E. C. (Ed.) (1991). After the Ice Age: The return of life to glaciated North America. Chicago, IL: University of Chicago Press. https://doi. org/10.7208/chicago/9780226668093.001.0001

Pielou, E. C. (Ed.) (1992). Biogeography. Malabar, FL: Krieger Publishing Company.

Prado, C. P. A., Haddad, C. F. B., \& Zamudio, K. R. (2012). Cryptic lineages and Pleistocene population expansion in a Brazilian Cerrado frog. Molecular Ecology, 21, 921-941. https://doi.org/10.1111/j.1365294X.2011.05409.x

Prance, G. T. (1982). A review of the phytogeographic evidences for Pleistocene climate changes in the Neotropics. Annals of the Missouri Botanical Garden, 69, 594-624. https://doi.org/10.2307/2399085

Prance, G. T. (1996). Islands in Amazonia. Philosophical Transactions of the Royal Society of London Series B-Biological Sciences, 351, 823-833. https://doi.org/10.1098/rstb.1996.0077

Pritchard, J. K., Stephens, M., \& Donnelly, P. (2000). Inference of population structure using multilocus genotype data. Genetics, 155, 945959.

Purcell, S., Neale, B., Todd-Brown, K., Thomas, L., Ferreira, M. A., Bender, D., \& Sham, P. C. (2007). PLINK: A tool set for whole-genome association and population-based linkage analyses. American Journal of Human Genetics, 81, 559-575. https://doi.org/10.1086/519795

Quijada-Mascareñas, J. A., Ferguson, J. E., Pook, C. E., Salomão, M. D. G., Thorpe, R. S., \& Wüster, W. (2007). Phylogeographic patterns of trans-Amazonian vicariants and Amazonian biogeography: The Neotropical rattlesnake (Crotalus durissus complex) as an example.
Journal of Biogeography, 34, 1296-1312. https://doi.org/10.1111/j. 1365-2699.2007.01707.x

$R$ Core Team (2017). R: A language and environment for statistical computing. Vienna, Austria: R Foundation for Statistical Computing.

Ratter, J. A., Bridgewater, S., \& Ribeiro, J. F. (2003). Analysis of the floristic composition of the Brazilian Cerrado vegetation III: Comparison of the woody vegetation of 376 areas. Edinburgh Journal of Botany, 60, 57-109.

Resende-Moreira, L. C., de Vasconcelos, P. N., Andrea, P. S. A., Menezes, A. P. A., Lemos-Filho, J. P., \& Lovato, M. B. (2017). East-west divergence in central Brazilian Cerrado revealed by cpDNA sequences of a bird-dispersed tree species. Biochemical Systematics and Ecology, 70, 247-253. https://doi.org/10.1016/j.bse.2016.12.007

Ribeiro, P. C., Lemos, J. P., Buzatti, R. S. D., Lovato, M. B., \& Heuertz, M. (2016). Species-specific phylogeographical patterns and Pleistocene east-west divergence in Annona (Annonaceae) in the Brazilian Cerrado. Botanical Journal of the Linnean Society, 181, 21-36. https://doi. org/10.1111/boj.12394

Rocha, A. E. S., \& Miranda, I. S. (2014). Poaceae communities in the savannas of the Amazon estuary in Brazil. Acta Botanica Brasilica, 28, 559-568. https://doi.org/10.1590/0102-33062014abb2812

Sanaiotti, T. M. (1997). Comparação fitossociológica de quatro savanas de Roraima. In R. I. Barbosa, E. J. G. Ferreira, \& E. G. Castellon (Eds.), Ambiente e Ecologia em Roraima (pp. 481-488). Manaus, Brazil: INPA.

Santos, M. G., Nogueira, C., Giugliano, L. G., \& Colli, G. R. (2014). Landscape evolution and phylogeography of Micrablepharus atticolus (Squamata, Gymnophthalmidae), an endemic lizard of the Brazilian Cerrado. Journal of Biogeography, 41, 1506-1519. https://doi.org/10. 1111/jbi.12291

Savit, A. Z., \& Bates, J. M. (2015). Right around the Amazon: The origin of the circum-Amazonian distribution in Tangara cayana. Folia Zoologica, 64, 273-283. https://doi.org/10.25225/fozo.v64.i3.a8.2015

Silva, J. M. C. (1995). Biogeographical analysis of the South American avifauna. Steenstrupia, 21, 49-67.

Silva, J. M. C., \& Bates, J. M. (2002). Biogeographic patterns and conservation in the South American Cerrado: A tropical savanna hotspot. BioScience, 52, 225-233. https://doi.org/10.1641/0006-3568(2002) 052[0225:BPACIT]2.0.CO;2

Slatkin, M. (1995). A measure of population subdivision based on microsatellite allele frequencies. Genetics, 139, 457-462.

Smith, S. A., \& Donoghue, M. J. (2008). Rates of molecular evolution are linked to life history in flowering plants. Science, 322, 86-89. https://doi.org/10.1126/science.1163197

Souza, H. A., Collevatti, R. G., Lima-Ribeiro, M. S., Lemos-Filho, J. P., \& Lovato, M. B. (2017). A large historical refugium explains spatial patterns of genetic diversity in a Neotropical savanna tree species. Annals of Botany, 119, 239-252. https://doi.org/10.1093/aob/mc w096

Strassburg, B. B. N., Brooks, T., Feltran-Barbieri, R., Iribarrem, A., Crouzeilles, R., Loyola, R., \& Balmford, A. (2017). Moment of truth for the Cerrado hotspot. Nature Ecology \& Evolution, 1, 0099. https://doi.org/ 10.1038/s41559-017-0099

Tamura, K., Peterson, D., Peterson, N., Stecher, G., Nei, M., \& Kumar, S. (2011). MEGA5: Molecular evolutionary genetics analysis using maximum likelihood, evolutionary distance, and maximum parsimony methods. Molecular Biology and Evolution, 28, 2731-2739. https://doi. org/10.1093/molbev/msr121

Thomaz, A. T., Malabarba, L. R., \& Knowles, L. L. (2017). Genomic signatures of paleodrainages in a freshwater fish along the southeastern coast of Brazil: Genetic structure reflects past riverine properties. Heredity, 119, 287-294. https://doi.org/10.1038/hdy.2017.46

van der Hammen, T. (1991). Paleoecological background: Neotropics. Climatic Change, 19, 37-47. https://doi.org/10.1007/BF00142211

Vargas-Ramírez, M., Maran, J., \& Fritz, U. (2010). Red- and yellowfooted tortoises, Chelonoidis carbonaria and C. denticulata (Reptilia: 
Testudines: Testudinidae), in South American savannahs and forests: Do their phylogeographies reflect distinct habitats? Organisms Diversity \& Evolution, 10, 161-172. https://doi.org/10.1007/ s13127-010-0016-0

Vieira, D. L. M., Aquino, F. G., Brito, M. A., Fernandes-Bulhão, C., \& Henriques, R. P. B. (2002). Síndromes de dispersão de espécies arbustivoarbóreas em cerrado sensu strictu do Brasil Central e savannas amazônicas. Brazilian Journal of Botany, 25, 215-220. https://doi.org/ 10.1590/S0100-84042002000200009

Vinson, S. B., Williams, H. J., Frankie, G. W., \& Shrum, G. (1997). Floral lipid chemistry of Byrsonima crassifolia (Malpigheaceae) and a use of floral lipids by Centris bees (Hymenoptera: Apidae). Biotropica, 1, 76-83.

Wang, X. F., Edwards, R. L., Auler, A. S., Cheng, H., Kong, X. G., Wang, Y. J., \& Chiang, H. W. (2017). Hydroclimate changes across the Amazon lowlands over the past 45,000 years. Nature, 541, 204-207. https://doi.org/10.1038/nature20787

Wang, C. L., Zöllner, S., \& Rosenberg, N. A. (2012). A quantitative comparison of the similarity between genes and geography in worldwide human populations. Plos Genetics, 8, e1002886. https://doi.org/10. 1371/journal.pgen.1002886

Webb, S. D. (1991). Ecogeography and the great American interchange. Paleobiology, 17, 266-280. https://doi.org/10.1017/S00948373 00010605

Werneck, F. P., Nogueira, C., Colli, G. R., Sites, J. W., \& Costa, G. C. (2012). Climatic stability in the Brazilian Cerrado: Implications for biogeographical connections of South American savannas, species richness and conservation in a biodiversity hotspot. Journal of Biogeography, 39, 1695-1706. https://doi.org/10.1111/j.1365-2699. 2012.02715.x

Willis, C. G., Franzone, B. F., Xi, Z., \& Davis, C. C. (2014). The establishment of Central American migratory corridors and the biogengraphic origins of seasonally dry tropical forests in Mexico. Frontier in Genetics, 5, 433.

Wüster, W., Ferguson, J. E., Quijada-Mascareñas, J. A., Pook, C. E., Salomão, M. D., \& Thorpe, R. S. (2005). Tracing an invasion: Landbridges, refugia, and the phylogeography of the Neotropical rattlesnake (Serpentes: Viperidae: Crotalus durissus). Molecular Ecology, 14, 1095-1108. https://doi.org/10.1111/j.1365-294X.2005.02471.x

Yang, Y., Moore, M. J., Brockington, S. F., Soltis, D. E., Wong, G. K. S., Carpenter, E. J., \& Smith, S. A. (2015). Dissecting molecular evolution in the highly diverse plant clade Caryophyllales using transcriptome sequencing. Molecular Biology and Evolution, 32, 2001-2014. https://doi.org/10.1093/molbev/msv081

\section{BIOSKETCH}

The authors are broadly interested in biogeographical and evolutionary history of the Neotropics. Together the authors bring different expertise, forming a complementary team that spans from sampling and data collection to hypothesis generation and testing about the Cerrado evolutionary history. This work was part of a collaboration between UFMG and the University of Michigan.

Author contributions: L.C.R.M., M.B.L., J.P.L.F., and L.L.K. designed the study; L.C.R.M., M.B.L., and J.P.L.F. collected samples; L.C.R.M., A.T.T., J.R.P., and A.P.S. generated data and performed data analysis; L.C.R.M., L.L.K., and M.B.L. wrote the paper and all authors contributed with comments.

\section{DATA ACCESSIBILITY}

Chloroplast DNA sequences are available on GenBank (accession numbers MK120204 - MK120271) and Illumina raw data were deposited at NCBI Sequence Read Archive (SRP158434).

\section{SUPPORTING INFORMATION}

Additional supporting information may be found online in the Supporting Information section at the end of the article.

How to cite this article: Resende-Moreira LC, Knowles LL, Thomaz AT, et al. Evolving in isolation: Genetic tests reject recent connections of Amazonian savannas with the central Cerrado. J Biogeogr. 2019;46:196-211. https://doi.org/ $10.1111 /$ jbi.13468 